\title{
Blood Group Rhesus D-negativity and Awareness Toward Importance of Anti-D Immunoglobulin Among Pregnant Women in Bisha, Saudi Arabia
}

\author{
Amar Yahia $^{1}$, Elhadi Miskeen ${ }^{2}$, Shahzada K. Sohail ${ }^{1}$, Tarig Algak $^{1}$, Saad Aljadran ${ }^{3}$ \\ 1. Basic Medical Sciences, College of Medicine, University of Bisha, Bisha, SAU 2. Obstetrics and Gynecology, College of \\ Medicine, University of Bisha, Bisha, SAU 3. Laboratory Medicine, King Abdullah Hospital, Bisha, SAU
}

Corresponding author: Amar Yahia, amarfigo2@yahoo.com

\section{Abstract \\ Background}

Rhesus D (RhD) antigen alloimmunization has been a focus of concern for hematologists and obstetricians. It contributes to perinatal morbidity and mortality. The objectives of this study were to assess the awareness of pregnant women toward the clinical importance of blood group $\mathrm{Rh}(\mathrm{D})$-negativity and anti-D immunoglobulin and to determine the prevalence of blood group Rh(D)-negativity among them.

\section{Methods and materials}

This cross-sectional study was conducted in a routine antenatal care clinic of King Abdullah Hospital in Bisha, Saudi Arabia from September 2018 to January 2019. The awareness of pregnant women toward the clinical importance of blood group Rh(D)-negativity and prophylaxis with anti-D immunoglobulin was assessed through a self-administered questionnaire. Samples were analyzed for $\mathrm{ABO}$ and $\mathrm{Rh}$ (D) blood groups using the microplate grouping method. The presence of anti-D alloantibodies was detected by the indirect antiglobulin test. Data were analyzed by IBM SPSS Statistics for Windows, Version 25.0 (Armonk, NY: IBM Corp.). A p-value $\leqslant 0.05$ was considered statistically significant.

\section{Results}

A total of 108 respondents fulfilled the inclusion criteria and completed the survey. Forty-five pregnant women (41.7\%) were observed to be aware of the blood group $\mathrm{Rh}(\mathrm{D})$-negativity and anti-D immunoglobulin issue. The prevalence of the negative blood group was $11.1 \%(12 / 108)$. Awareness was found to be significantly associated with age, education, vaginal bleeding, blood groups, and previous administration of anti-D immunoglobulin ( $\mathrm{p}$-value $\leqslant 0.05$ ).

\section{Conclusion}

Received 02/06/2020 Review began 02/09/2020 Review ended 02/15/2020 Published 02/19/2020

(c) Copyright 2020 Yahia et al. This is an open access article distributed under the terms of the Creative Commons Attribution License CC-BY 4.0., which permits unrestricted use, distribution, and reproduction in any medium, provided the original author and source are credited.
The prevalence of blood group $\mathrm{Rh}(\mathrm{D})$-negativity among respondents was found to be comparative with other populations, although the overall awareness was found to be suboptimal (41.7\%). Structured health education programs by hematologists and obstetricians are needed to increase awareness and to address women at reproductive age.

\begin{abstract}
Categories: Obstetrics/Gynecology, Public Health, Hematology
Keywords: rhesus d antigen alloimmunization, blood group rh(d)-negativity, anti-d immunoglobulin, awareness

Introduction

Rhesus D (RhD) antigen alloimmunization has been a focus of concern for hematologists and obstetricians due to its significant contribution to perinatal morbidity and mortality as a consequence of hemolytic disease of the fetus and the newborn (HDFN). Rhesus alloimmunization represents an avoidable direct cause for perinatal morbidity and mortality, so health education sittings are needed to increase the awareness of the public about this important issue [1,2]. Screening of pregnant women for blood groups has been well established and widely practiced in the antenatal care clinic. The introduction of anti-D prophylaxis has significantly reduced perinatal deaths from alloimmunization by approximately 100 -fold $[3,4]$. Administration of anti-D immunoglobulin is an effective protective measure in reducing the risk of HDFN $[3,5]$. The aim of this study was to assess the awareness of pregnant women toward the clinical importance of blood group Rh(D)-negativity and anti-D immunoglobulin at King Abdulla Hospital in Bisha, Saudi Arabia as well as to determine the prevalence of blood group $\mathrm{Rh}(\mathrm{D})$-negativity among pregnant women in the local population.
\end{abstract}

\section{Materials And Methods}




\section{Study design and setting}

This cross-sectional study was conducted in a routine antenatal care clinic of King Abdullah Hospital in Bisha from September 2018 to January 2019. This is the main tertiary hospital in Bisha and serves a wide range of the population in 240 villages.

\section{Study population and data collection}

A total of 108 pregnant women verbally consented and participated in the study. Awareness of the respondents toward the clinical importance of blood group $\mathrm{Rh}(\mathrm{D})$-negativity and prophylaxis with anti-D immunoglobulin was assessed through a self-administered questionnaire. The questionnaire design and content validity were checked and approved by a research committee at the College of Medicine, University of Bisha. The questionnaire consisted of socio-demographic characteristics, blood group, parity, history of vaginal bleeding in early pregnancy, previous administration of anti-D immunoglobulin, and variables that assessed respondents' awareness toward the clinical importance of blood group Rh(D)-negativity and anti-D immunoglobulin. The questionnaire was translated into Arabic and subjected to a process of forward and backward translation. The study was approved by the institutional review board of King Abdulla Hospital.

\section{Method of testing blood group Rh (D)}

Peripheral blood was drawn into ethylenediaminetetraacetic acid-containing vacutainer tubes. Samples were analyzed for $\mathrm{ABO}$ and $\mathrm{Rh}(\mathrm{D})$ blood groups using the microplate grouping method. The presence of anti-D alloantibodies was detected by the indirect antiglobulin test, which involved the incubation of standard cells with the test serum at $37^{\circ} \mathrm{C}$ for 30 minutes and then reacting with anti-human globulin to bring about agglutination of the red cells in positive samples.

\section{Statistical analysis}

Data were analyzed using IBM SPSS Statistics for Windows, Version 25.0 (Armonk, NY: IBM Corp.). Categorical variables were described using frequencies and percentages. A univariate analysis was conducted using a chi-squared test for these variables. A p-value of $\leqslant 0.05$ was considered statistically significant.

\section{Results}

A total of 108 respondents fulfilled the inclusion criteria and completed the survey. Most respondents$71 / 108$ (65.7\%)-were within the age group of 18-35 years. Only one-quarter of respondents-27/108 (25.0\%)had achieved a university-level education. Forty-five pregnant women (41.7\%) were observed to be aware of the blood group Rh(D)-negativity and anti-D immunoglobulin issue. This study found a statistically significant association of this awareness with increasing age and education level of the respondents with pvalues of 0.035 and 0.001 , respectively. In this study, $77 / 108$ (71.3\%) of the respondents were parous women. About one-third of those parous women-37/108 (34.3\%)-have experienced vaginal bleeding during pregnancy, which showed a statistically significant association with their awareness ( $p$-value $=0.000$; Table 1). The prevalence of the negative blood group was $11.1 \%(12 / 108)$. The most common blood group among the study population was O positive, 44/108 (40.7\%). The distribution of other blood groups is shown in Figure 1 . The association between blood group type and awareness showed a statistically significant result ( $\mathrm{p}$-value $=0.001$ ). Among the study population with negative blood groups, the majority-10/11 (91.6\%)-had received anti-D immunoglobulin; however, one patient was not sure about receiving the anti-D immunoglobulin. A strong association was found between the previous administration of anti-D immunoglobulin and awareness ( $\mathrm{p}$-value $=0.000$; Figure 2 ). 


\section{Cureus}

\begin{tabular}{|c|c|c|c|c|}
\hline Characteristics & Aware & Not Aware & Total (\%) & P-value \\
\hline \multicolumn{5}{|l|}{ Age group in years } \\
\hline Younger than 18 & $6(5.6 \%)$ & $10(9.3 \%)$ & $16(14.8 \%)$ & \multirow{3}{*}{0.035} \\
\hline $18-35$ & $25(23.2 \%)$ & 46 (42.6\%) & $71(65.7 \%)$ & \\
\hline Older than 35 & $14(13.0 \%)$ & $7(6.5 \%)$ & $21(19.4 \%)$ & \\
\hline \multicolumn{4}{|l|}{ Educational level } & \multirow{4}{*}{0.001} \\
\hline University & $25(23.2 \%)$ & $2(1.9 \%)$ & 27 (25.0\%) & \\
\hline Secondary & $13(12.0 \%)$ & $30(27.8 \%)$ & $43(39.8 \%)$ & \\
\hline Primary & $7(6.5 \%)$ & $31(28.7 \%)$ & $38(35.2 \%)$ & \\
\hline \multicolumn{4}{|l|}{ Parity } & \multirow{3}{*}{0.105} \\
\hline Primigravida & $8(7.4 \%)$ & $23(21.3 \%)$ & $31(28.7 \%)$ & \\
\hline Parous & $37(34.3 \%)$ & $40(37.0 \%)$ & 77 (71.3\%) & \\
\hline \multicolumn{4}{|c|}{ Vaginal bleeding in early pregnancy } & \multirow{3}{*}{0.000} \\
\hline Yes & $29(26.9 \%)$ & $8(7.4 \%)$ & 37 (34.3\%) & \\
\hline No & $16(14.8 \%)$ & $55(50.9 \%)$ & $71(65.7 \%)$ & \\
\hline
\end{tabular}

TABLE 1: Characteristics of the study population and association with their awareness $(\mathrm{N}=108)$

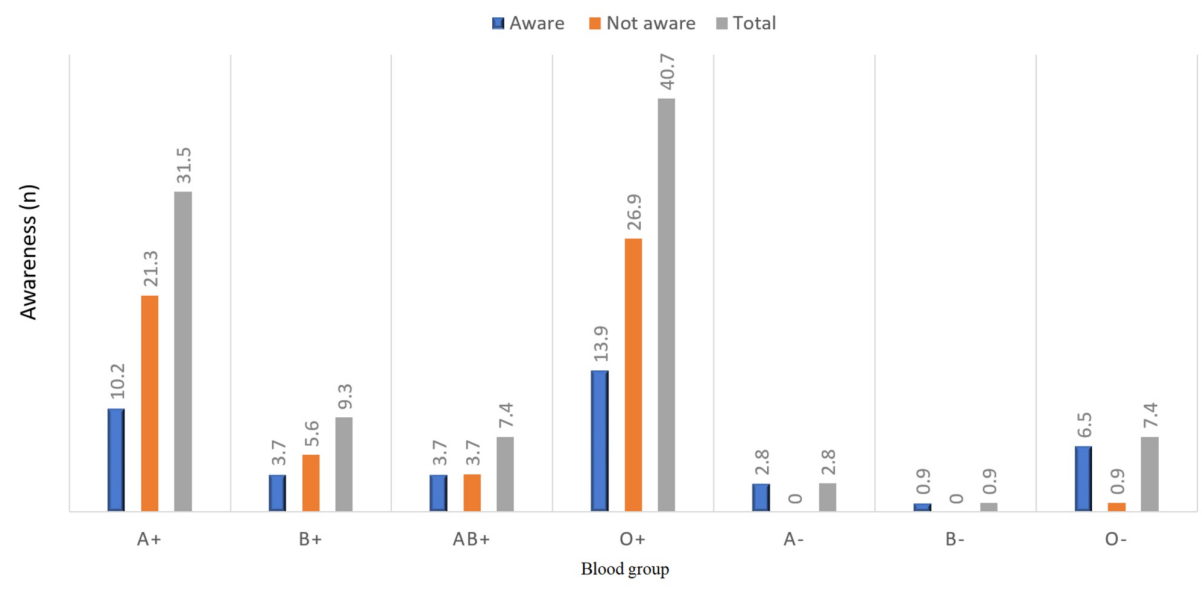

FIGURE 1: Distribution of blood groups and its association with the awareness $(\mathrm{N}=108)$ 


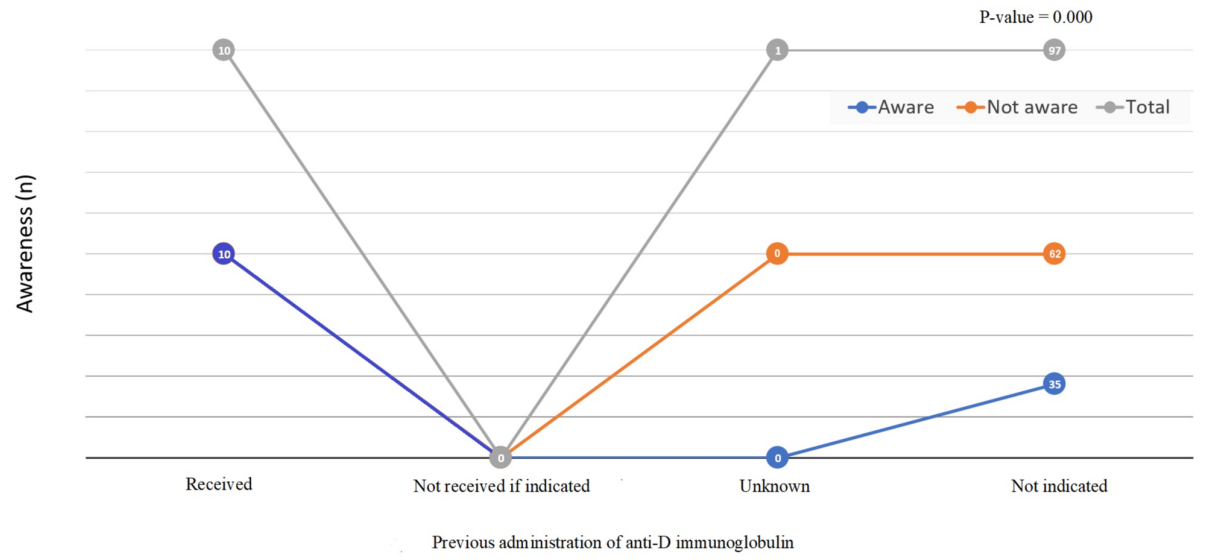

FIGURE 2: Previous administration of anti-D immunoglobulin and its association with the awareness $(\mathrm{N}=108)$

\section{Discussion}

This study provided valuable results regarding important daily practice issues: blood group $\mathrm{Rh}(\mathrm{D})$-negativity and the importance of anti-D immunoglobulin. Prevalence, awareness, and importance of anti-D immunoglobulin were assessed in the main tertiary hospital in Bisha, Saudi Arabia. The prevalence of negative blood groups among pregnant women in this study was $11.1 \%$. The prevalence of $\mathrm{Rh}(\mathrm{D})$-negative blood groups varies in ethnic populations, with approximately $15.8 \%$ of Caucasians, $8 \%$ of Blacks, and $1 \%$ of Asians [6]. The prevalence of negative blood group revealed by this study is more than that reported by the Netherlands (8.9\%), a previous Saudi study (7.5\%), Nigeria (4.5\%), and Oman (7.3\%), and it is less than that reported by Pakistan (13.6\%) [6-10]. This finding appears to be comparable with other ethnic groups. The antenatal administration of anti-D immunoglobulin prophylaxis is necessary for all Rh(D)-negative women [11]. The overall awareness of the blood group $\mathrm{Rh}(\mathrm{D})$-negativity and the clinical importance of anti-D immunoglobulin was found to be suboptimal (41.7\%) in our study; however, a statistically significant association was found among awareness regarding this important clinical issue and blood group type, previous administration of anti-D immunoglobulin, age, educational level, and previous experience of vaginal bleeding. Our study showed that the highest level of awareness was associated with the previous reception of anti-D immunoglobulin (100\%) and among women with negative blood groups (91.6\%). This finding might be due to their previous experience with the same issue. This study also reflected increased awareness among older women and higher education categories. The level of awareness among our study population was higher compared to that of Nigeria, where awareness of maternal-fetal blood incompatibility of expectant mothers was reported to be 39\% [12]. A previous study from Saudi Arabia showed that only $38 \%$ of the studied mothers had awareness about $\mathrm{Rh}(\mathrm{D})$ incompatibility, $68.5 \%$ had awareness about anti-D immunoglobulin, and 51\% had awareness about the time of administration of anti-D immunoglobulin [13]. A study in Singapore reported that only $49.1 \%$ of women had adequate awareness and $40.0 \%$ and $10.9 \%$ of the participants had inadequate and poor knowledge, respectively [14].

\section{Conclusions}

The prevalence of blood group Rh(D)-negativity among respondents was found to be comparable with other populations. The overall awareness of the blood group $\mathrm{Rh}(\mathrm{D})$-negativity and the clinical importance of antiD immunoglobulin was found to be suboptimal in our study. Structured health education programs by obstetricians are needed to increase awareness and to address women at reproductive age.

\section{Additional Information \\ Disclosures}

Human subjects: Consent was obtained by all participants in this study. Institutional Review Board King Abdullah Hospital, Bisha KSA issued approval Not applicable. Animal subjects: All authors have confirmed that this study did not involve animal subjects or tissue. Conflicts of interest: In compliance with the ICMJE uniform disclosure form, all authors declare the following: Payment/services info: All authors have declared that no financial support was received from any organization for the submitted work. Financial relationships: All authors have declared that they have no financial relationships at present or within the previous three years with any organizations that might have an interest in the submitted work. Other relationships: All authors have declared that there are no other relationships or activities that could appear to have influenced the submitted work. 


\section{Acknowledgements}

The authors would like to thank the administration and staff of College of Medicine University of Bisha and King Abdullah Hospital for their valuable role in completing this study. Great thanks to all respondents for agreeing to participate in the study.

\section{References}

1. Mollison PL, Engelfriet DP, Contreras M: Blood Transfusion in Clinical Medicine, 10th edition. Blackwell Science, Oxford, United Kingdom; 2006. 10.1046/j.1365-2044.1999.01037.x

2. Urbaniak SI, Greiss MA: RhD haemolytic disease of the fetus and the newborn. Blood Rev. 2000, 14:44-61. 10.1054/blre.1999.0123

3. Kumar S, Regan F: Management of pregnancies with RhD alloimmunisation. BMJ. 2005, 330:1255-1258. 10.1136/bmj.330.7502.1255

4. Routine antenatal anti-D prophylaxis for women who are rhesus D negative . (2008). Accessed: December 18, 2019: https://www.nice.org.uk/guidance/ta156..

5. Gajjar K, Spencer C: Diagnosis and management of non-anti-D red cell antibodies in pregnancy . Obstet Gynaecol. 2009, 11:89-95. 10.1576/toag.11.2.089.27481

6. Avent ND, Reid ME: The Rh blood group system: a review . Blood. 2000, 95:375-387. 10.1182/blood.V95.2.375

7. Bondagii NS: Rhesus alloimmunization in pregnancy. A tertiary care center experience in the Western region of Saudi Arabia . Saudi Med J. 2011, 32:1039-1045.

8. Karim F, Moiz B, Kamran N: Risk of maternal alloimmunization in Southern Pakistan-a study in a cohort of 1000 pregnant women. Transfus Apher Sci. 2015, 52:99-102. 10.1016/j.transci.2014.12.002

9. Okeke TC, Ocheni S, Nwagha UI, Ibegbulam OG: The prevalence of Rhesus negativity among pregnant women in Enugu, Southeast Nigeria. Niger J Clin Pract. 2012, 15:400-402. 10.4103/1119-3077.104511

10. Al-Dughaishi T, Al Harrasi Y, Al-Duhli M, et al.: Red cell alloimmunization to Rhesus antigen among pregnant women attending a tertiary care hospital in Oman. Oman Med J. 2016, 31:77-80. 10.5001/omj.2016.15

11. Dajak S, Roje D, Hašpl ŽH, Maglić PE: The importance of antenatal prevention of RhD immunisation in the first pregnancy. Blood Transfus. 2014, 12:410-415. 10.2450/2014.0167-13

12. Kio JO, Agbede CO, Oroniyi FA: Assessing expectant mothers' knowledge and practices regarding maternalfetal blood incompatibility: evidence from Ogun State, Nigeria. Greener J Epidemiol Public Health. 2016, 4:013-019. 10.15580/GJEPH.2016.2.100216152

13. Aljuhaysh RM, El-Fetoh NMA, Alanazi MI, et al.: Maternal-fetal Rhesus (Rh) factor incompatibility in Arar, northern Saudi Arabia. Electron Physician. 2017, 9:5908-5913. 10.19082/5908

14. Wee WW, Kanagalingam D: The use of anti-D immunoglobulins for rhesus prophylaxis: audit on knowledge and practices among obstetricians. Singapore Med J. 2009, 50:1054-1057. 